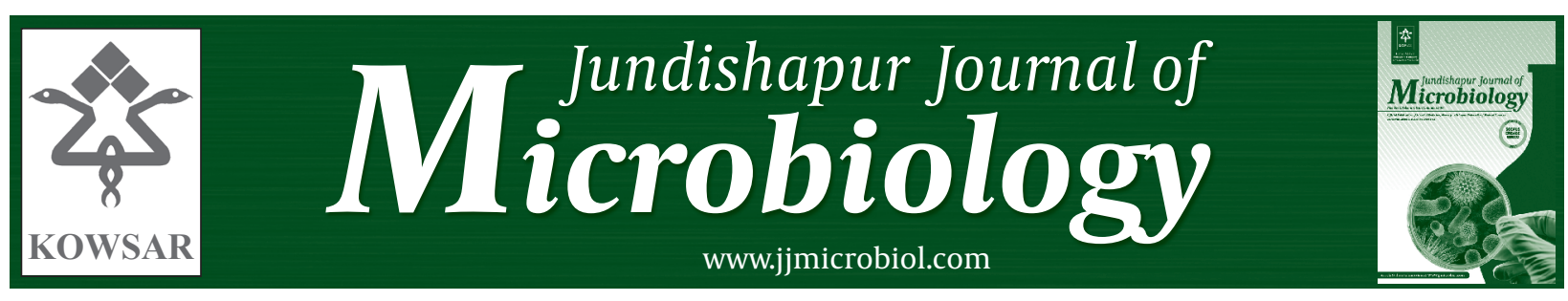

\title{
Evaluation of Two Immunodiagnostic Assays (MAT and IFA) for Human Leptospirosis in Gilan Province - Iran
}

\author{
Nooshin Khandan Dezfully ${ }^{1}$, Sedighe Mehrabian ${ }^{1^{*}}$ \\ ${ }^{1}$ Department of Microbiology, Faculty of Biosciences, Islamic Azad University, Tehran North Branch, Tehran, IR Iran
}

\begin{tabular}{|c|c|}
\hline A R T I C L E I N F O & A B S T R A C T \\
\hline $\begin{array}{l}\text { Article type: } \\
\text { Original Article }\end{array}$ & $\begin{array}{l}\text { Background: Leptospirosis is a systemic infectious disease caused by pathogenic bac- } \\
\text { teria belonging to the species of Leptospira, it is considered to be the most common zo- } \\
\text { onosis in the world. This is a serious and sometimes fatal infection which is transmitted }\end{array}$ \\
\hline $\begin{array}{l}\text { Article history: } \\
\text { Received: } 02 \text { Feb } 2012 \\
\text { Revised: } 15 \text { Feb } 2012 \\
\text { Accepted: } 22 \text { Feb } 2012\end{array}$ & $\begin{array}{l}\text { from animals to humans by entering the digestive tract or mucosal membrane. Within } \\
\text { the initial 10-12 day period, the patient may experience no or relatively minor symptoms, } \\
\text { then the bacteria enters the blood system and causes contamination of the internal or- } \\
\text { gans, especially the liver. }\end{array}$ \\
\hline $\begin{array}{l}\text { Keywords: } \\
\text { Leptospirosis } \\
\text { Microscopic Agglutination Test } \\
\text { Indirect Immunofluorescence Assay }\end{array}$ & $\begin{array}{l}\text { glutination test(MAT) and indirect immunofluorescence assay (IFA) with the aim of identify- } \\
\text { ing leptospiral agents quickly, in order to prevent and control leptospirosis diseases. } \\
\text { Patients and Methods: In this study, } 90 \text { blood samples and their serums, were collected } \\
\text { from patients showing clinical symptoms of leptospirosis, and these were analyzed with } \\
\text { MAT and IFA tests, to test for the presence of leptospiral agglutinins. In this study we } \\
\text { used five serogroups of Leptospira interrogans, which have been identified as the domi- } \\
\text { nant serogroups in Iran (Pomona, Canicola, Grippotyphosa, Icterohaemorrhagiae and } \\
\text { Sejro hardjo). } \\
\text { Results: The results obtained showed that when compared to the IFA, the MAT was a } \\
\text { more sensitive test. The IFA method also identified certain specific properties of the se- } \\
\text { rogroups; Pomona, Canicola and Icterohaemorragiae, which are detailed in the article. } \\
\text { Conclusions: Serological testing is the most widely used method for diagnosing lepto-- } \\
\text { spirosis, and the MAT is considered to be the gold standard test for the diagnosis and } \\
\text { detection of leptospiral antibodies in both human and animal sera, for the infecting se- } \\
\text { rovar and serogroup. }\end{array}$ \\
\hline
\end{tabular}

Published by Kowsar Corp, 2012. cc 3.0.

Implication for health policy/practice/research/medical education:

With respect to the numerous reports based on acute and chronic forms of leptospirosis (in human and animal population) outbreaks in Iran, and to prevent economic and health associated losses.

Please cite this paper as:

Khandan Dezfully N, Mehrabian S. Evaluation of Two Immunodiagnostic Assays (MAT and IFA) for Human Leptospirosis in Gilan Province -Iran. Jundishapur J Microbiol. 2012;5(4):582-4. DOI:10.5812/jjm.4564

\section{Background}

One of the important factors that have affected human health over the years is infectious diseases. Among these diseases, transmissible diseases between animals and hu-

\footnotetext{
* Corresponding author: Sedighe Mehrabian, Department of Microbiology, Faculty of Biosciences, Islamic Azad University, Tehran North Branch, Tehran, IR Iran. Tel:+98-2188848940, Fax:+98-2188848940,_E-mail: mehrabian_s@yahoo.com permits unrestricted use, distribution, and reproduction in any medium, provided the original work is properly cited.
} 
mans are considered to be significant. At present, more than 450 diseases are known to be transmitted between animals and humans. They are a serious danger to public health, economic development, business and the tourism industry, especially in developing countries. Leptospirosis is a severe, fever causing, systemic, zoonotic disease that is caused by pathogenic spiral bacteria which belong to the species Leptospira interrogans. These bacteria are placed in to the family Leptospiraceae, and the order Spirochaetales (1).

These spirochetes are finely coiled, thin, motile, slow growing aerobic, gram-negative bacteria which are transmitted to humans through contact of the mucous membranes or abraded skin with a contaminated environmental source (e.g. water, food, contact with the urine of an infected animal) (2). Leptospirosis was first recognized as an "occupational disease" in 1983. It is common among; farm workers, veterinarians, and agriculture field workers with a worldwide distribution, which is generally associated with humid subtropical or tropical climates (heavy rainfall) and it has endemic potential. Laboratory diagnosis of human leptospirosis relies on either the isolation of etiological organisms from the specimen or the demonstration of specific antibodies which arise in the serum (3). Isolation is laborious, time consuming, expensive, and has low sensitivity (4). Direct demonstration of leptospires in preparations from clinical specimens by dark-field microscopy, direct immunofluorescence and immunoperoxidase staining has been hampered by a lack of specificity, due to the non-specific background (5).

\section{Objectives}

This study prospectively evaluated two serological methods, the microscopic agglutination test (MAT) and the indirect immunofluorescence assay (IFA), with the aim of identifying leptospiral agents in order to prevent and control leptospirosis diseases in the quickest possible time.

\section{Patients and Methods}

Serum samples were collected from 90 people who were suspected of having leptospirosis. These patients had shown an acute fever $\left(38^{\circ} \mathrm{C}\right)$ for more than one day, but not exceeding three weeks, and had been referred to the health center of the Gilan Province (Iran). All collected serum samples were kept at $-20^{\circ} \mathrm{C}$ for analysis with both MAT and IFA methods.

\subsection{Microscopic Agglutination Test (MAT)}

The MAT followed a modified Galton technique (6), 4 to 14 day old cultures of predominant serogroups of Leptospira in a broth media were incubated at $28^{\circ}-30^{\circ} \mathrm{C}$ with the density $10^{4}$. used as a live antigen. In this study we used five predominant serogroups of L. interrogans which are the most commonly known in Iran; Pomona, Canicola, Grippotyphosa, Icterohaemorrhagiae and Sejro hardjo. A ratio of $50 \mu \mathrm{l}$ of serum was diluted 1:100 with phosphate buffer saline (PBS), and this was added to 23 wells of a microtiter plate, then $50 \mu$ l of each live Leptospira serovar was added to each well. The specimen was mixed gently after leaving for two hours in an incubator at $28-30^{\circ} \mathrm{C}$, the suspension was dropped onto a slide (wet mount) and the amount of motility of the Leptospira agents was observed under a dark field microscope at a final magnification of 400x. Any serum specimen with a positive reaction was then tested against the respective server to determine the endpoint titer which gave the highest dilution having more than $50 \%$ agglutination of the leptospires. The serovar giving the highest titer was considered to be the infecting serovar.

\subsection{Indirect Immunofluorescence Assay (IFA)}

The IFA was performed using a modified test (7). In the IFA method, five serovars of L. interrogans were used as antigens; Icterohaemorrhagiae, Grippotyphosa, Pomona, Sejro hardjo, and Canicola, which had been fixed with normal yolk sacs. These were put on a slide and wrapped with aluminum foil, and then stored at $20^{\circ} \mathrm{C}$ until used. $10 \mu \mathrm{l}$ of the diluted serum (starting at $5 \mu \mathrm{l}$ ) was added to the slide and incubated at room temperature in a moist chamber for 30 minutes. The slide was washed with phosphate buffer saline $\mathrm{pH}$ : 7.2 three times (for 10-15 min each time), and air dried. $10 \mathrm{ml}$ of optimal dilution fluorescein isothiocyanate conjugated rabbit anti-human immunoglobulin (Ig G) along with Evans blue (DAKO, Denmark) was placed on the slide and incubated at room temperature in a moist chamber for $30 \mathrm{~min}$. The slide was washed with phosphate buffer saline as previously done. The slide was examined under a fluorescent microscope. All positive sera were further diluted until the highest final serum dilution giving a visible fluorescence of the leptospires was found. Positive and negative reference servers were included in each batch tested.

\section{Results}

A total of 90 serum samples belonging to those who were suspected to have leptospirosis were evaluated for leptospiral antibodies using two serological methods, the MAT and IFA tests. Out of the 90 serum samples which were tested by the MAT method, 64 samples (71.11\%) showed positive serum reactions (a titer above 1/100) and 26 samples (28.88\%) had a negative serum reaction to leptospiral serovars. The results of the IFA test showed that 42 cases (46.66\%) had a positive serum reaction (a titer above $1 / 16$ ) and 48 cases (53.33\%) had a negative serological reaction to the leptospiral serovars. Also, the highest antibody titer against Leptospiral serogroups in the MAT and IFA tests respectively was 1/200 and 1/32. 
MAT and IFA tests were used with the five leptospiral serogroups that are the most commonly known in Iran; Icterohaemorrhagiae, Sejro hardjo, Canicola, Pomona, and Grippotyphosa. With respect to the results of the outcomes of these two diagnostic methods (MAT and IFA), the most common serovars that the patients showed a positive serum reaction were related to; Icterohaemorrhagiae (35 No.), Canicola (21 No.), Pomona (10 No.), and Sejro hardjo (1 No.) in the MAT test and Icterohaemorrhagiae (18 No.), Pomona (17 No.), Canicola (15 No.), Grippotyphosa (5 No.), and Sejro hardjo (5 No.) in the IFA test respectively (Table.) achievable only in reference laboratories. In the IFA method which uses non-live antigens there is a low risk of contamination while using. This method is suitable for the detection of leptospiral antibodies in a routine clinical laboratory. This test also has some limitations, such as it requires a fluorescent microscope and technical expertise. Hence, this investigation suggests that it is better for the serum samples to be collected from routine local public health laboratories for later analysis at the reference centers. In reference centers the main identification and determination of serum titer will be conducted in the same way as in other countries.

\begin{tabular}{lllll}
\hline \multicolumn{5}{l}{ Table. Rate and Percentage of Seropositive Antibodies Using Two Methods (IFA and MAT) } \\
\hline & IFA $^{\text {a }}>\mathbf{1 / 1 6}$ & MAT $^{\mathrm{a}}>\mathbf{1 / 1 0 0}$ & Seropositive, No. & Percentage of Positive Sera \\
\hline Icterohaemorrhagiae & 18 & 35 & 53 & $58.8 \%$ \\
Pomona & 17 & 10 & 27 & $30 \%$ \\
Canicola & 15 & 21 & 36 & $40 \%$ \\
Sejro hardjo & 5 & 1 & 5 & $5.55 \%$ \\
Grippotyphosa & 5 & 0 & 5 & $5.55 \%$ \\
\hline
\end{tabular}

a Abbreviations: IFA, Indirect immunofluorescence assay; MAT, Microscopic agglutination test

The results of this study showed that the MAT method is more sensitive and specific than the IFA method, but the IFA method showed a specific quality to the serogroups; Pomona Grippotyphosa, and Sejro hardjo.

\section{Discussion}

According to numerous reports based on acute and chronic outbreaks of leptospirosis in Iran among human and animal populations, it is essential to pay greater attention and give quicker recognition to the agents which cause this disease, along with better control and prevention, because it is both a health and an economic problem. The province of Gilan (Iran) due to its geographical location (it lies on the shores of the Caspian Sea and it also has several neighboring countries including Azerbaijan, mild weather, moist climatic conditions) and many people make their living from growing rice in flooded fields, which is an environment conducive for the survival and spread of leptospirosis. According to seroepidemiological studies of leptospirosis, with the aim of identification of the most common Leptospiral serogroups in polluted centers in iran, Five serogroups of L. interrogans contain; Icterohaemorrhagiae, Sejro hardjo, Grippotyphosa, Canicola, and Pomona were identified (8).

Serological testing is the most widely used means for diagnosing leptospirosis, and the MAT is considered to be the gold standard test for the diagnosis and detection of leptospiral antibodies in human and animal sera for the infecting serovar and serogroup (2), however, the MAT test has some limitations in a routine clinical laboratory because it requires a battery of live antigens (maintaining a stock of live cultures) which creates high risk of contamination while using and it is also time consuming, hence this test is

\section{Acknowledgements}

The authors wish to thank the Razi Vaccine and Serum Research Institute, Karaj, Tehran, Iran for their kindly cooperation.

\section{Financial Disclosure}

None Declared.

\section{Funding Support}

None Declared.

\section{References}

1. Bergey DH, Holt JG. Bergey's Manual of Determinative Bacteriology. Baltimore, Md. [u.a.]: Williams \& Wilkins; 1994.

2. Levett PN. Leptospirosis. Clin Microbiol Rev. 2001;14 (2):296-326.

3. Winslow WE, Merry DJ, Pirc ML, Devine PL. Evaluation of a commercial enzyme-linked immunosorbent assay for detection of immunoglobulin M antibody in diagnosis of human leptospiral infection. J Clin Microbiol. 1997;35 (8):1938-42.

4. Levett PN, Whittington CU. Evaluation of the indirect hemagglutination assay for diagnosis of acute leptospirosis. J Clin Microbiol.1998;36 (1):11-4.

5. Saengjaruk P, Chaicumpa W, Watt G, Bunyaraksyotin G, Wuthiekanun V, Tapchaisri P, et al. Diagnosis of human leptospirosis by monoclonal antibody-based antigen detection in urine. J Clin Microbiol. 2002;40 (2):480-9.

6. Galton MM, Sulzer CR, Santarosa CA, Fields MJ. Application of a Microtechnique to the Agglutination Test for Leptospiral Antibodies. Appl Microbiol.1965;13:81-5.

7. Appassakij H, Silpapojakul K, Wansit R, Woodtayakorn J. Evaluation of the immunofluorescent antibody test for the diagnosis of human leptospirosis. Am J Trop Med Hyg. 1995;52 (4):340-3.

8. Yosefi JV. Report of research on seroepidemiological studies in leptospirosis and identification of the polluted centers in Iran. Arc Razi Ins. 2001. 